\title{
Molecular and biochemical characterization of a novel isoprene synthase from Metrosideros polymorpha
}

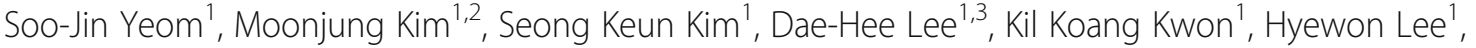 \\ Haseong Kim ${ }^{1,3}$, Dong-Myung Kim² and Seung-Goo Lee ${ }^{1,3^{*}}$
}

\begin{abstract}
Background: Isoprene is a five-carbon chemical that is an important starting material for the synthesis of rubber, elastomers, and medicines. Although many plants produce huge amounts of isoprene, it is very difficult to obtain isoprene directly from plants because of its high volatility and increasing environmental regulations. Over the last decade, microorganisms have emerged as a promising alternative host for efficient and sustainable bioisoprene production. Isoprene synthase (IspS) has received much attention for the conversion of isoprene from dimethylallyl diphosphate (DMAPP). Herein, we isolated a highly expressible novel IspS gene from Metrosideros polymorpha (MplspS), which was cloned and expressed in Escherichia coli, using a plant cDNA library and characterized its molecular and biochemical properties.

Results: The signal sequence deleted MplspS was cloned and expressed in E. coli as a 65-kDa monomer. The maximal activity of the purified Mplsps was observed at pH 6.0 and $55^{\circ} \mathrm{C}$ in the presence of $5 \mathrm{mM} \mathrm{Mn}^{2+}$. The $K_{\mathrm{m}}$ $k_{\text {cat }}$ and $k_{\text {cat }} / K_{m}$ for DMAPP as a substrate were $8.11 \mathrm{mM}, 21 \mathrm{~min}^{-1}$, and $2.59 \mathrm{mM}^{-1} \mathrm{~min}^{-1}$, respectively. MplspS was expressed along with the exogenous mevalonate pathway to produce isoprene in $E$. coli. The engineered cells produced isoprene concentrations of up to $23.3 \mathrm{mg} / \mathrm{L}$ using glycerol as the main carbon source.

Conclusion: MplspS was expressed in large amounts in E. coli, which led to increased enzymatic activity and resulted in isoprene production in vivo. These results demonstrate a new IspS enzyme that is useful as a key biocatalyst for bioisoprene production in engineered microbes.
\end{abstract}

Keywords: Isoprene synthase, DMAPP, Escherichia coli, Mevalonate pathway

\section{Background}

Isoprene (2-methyl-1,3-butadiene) is a volatile five-carbon terpene that is an important platform chemical in the synthetic chemistry industry for the synthesis of rubber, pharmaceuticals, flavors, and potential biofuels [1-5]. Almost all isoprene has been produced from petrochemical sources, mainly by direct isolation from C5 cracking fractions or through the dehydrogenation of C5 isoalkanes and isoalkenes [6, 7]. However, the C5

\footnotetext{
* Correspondence: sglee@kribb.re.kr

'Synthetic Biology and Bioengineering Research Center, KRIBB, Daejeon 34141, Republic of Korea

${ }^{3}$ Department of Biosystems and Bioengineering, KRIBB School of

Biotechnology, University of Science and Technology, Daejeon 34113,

Republic of Korea

Full list of author information is available at the end of the article
}

supply has been dependent upon the petroleum industry and the chemical production process is relatively energy-intensive and environment-unfriendly, and the yields may be insufficient for future demands [8].

To overcome these disadvantages, bioisoprene has become an attractive alternative. Bioisoprene is synthesized by isoprene synthase (IspS; EC 4.2.3.27) from dimethylallyl diphosphate (DMAPP). IspSs have been isolated and characterized from several plants, such as kudzu [9], poplars [10], aspen [11, 12], velvet bean [13], willows [5], and oaks [14]. Some IspSs have also been also employed to produce isoprene in Escherichia coli [15-19], Saccharomyces cerevisiae [20], Synechocystis [21], and Bacillus subtilis [22]. Although isoprene has been produced from these engineered microorganisms, their production level

(c) The Author(s). 2018 Open Access This article is distributed under the terms of the Creative Commons Attribution 4.0 International License (http://creativecommons.org/licenses/by/4.0/), which permits unrestricted use, distribution, and reproduction in any medium, provided you give appropriate credit to the original author(s) and the source, provide a link to the Creative Commons license, and indicate if changes were made. The Creative Commons Public Domain Dedication waiver (http://creativecommons.org/publicdomain/zero/1.0/) applies to the data made available in this article, unless otherwise stated. 
remains insufficient to satisfy the supply needed by industry [19]. As IspS is the key enzyme for the isoprene biosynthetic pathway needs to be established. Identification of new IspSs may provide enzymes with improved kinetics that will benefit the constructed microbial cell factories for efficient isoprene production.

In this study, our goal was to isolate a new IspS from a plant cDNA library and functionally characterize the IspS in E. coli. We mined transcriptome datasets of various plants to identify an IspS homologue. Among seven plants, a putative IspS was discovered from Metrosideros polymorpha, which emits volatile terpene [23]. However, emission of isoprene or IspS from $M$. polymorpha has not been reported. The gene encoding the putative IspS from M. polymorpha (MpIspS) was cloned and expressed in E. coli. The biochemical properties of the purified MpIspS, such as the effects of metal ions, $\mathrm{pH}$, temperature, and kinetics, were investigated. Finally, the characterized MpIspS successfully produced isoprene in E. coli harboring an exogenous mevalonate (MVA) pathway. MpIspS could be used as a potential enzyme for the production of isoprene in an $E$. coli system.

\section{Results and discussion}

\section{Discovery of new IspS}

An IspS homologue was identified from a plant cDNA library using gene-mining (OmicsPia Co. Ltd., Daejeon, Korea). The detailed method for the mining of IspS is described in the Methods section. We identified an IspS from $M$. polymorpha, which is a species of flowering evergreen tree in the myrtle family. For the MpIspS in this study, sequence alignments were performed and analyzed in detail by comparison with previously reported IspS sequences. A phylogenetic tree and a multiple sequence alignment indicating key amino acid positions in various IspSs are shown in Fig. 1a and b. The other genes previously proposed as the ispS genes of Eucalyptus grandis, Melaleuca alternifolia, Vitis vinifera, Camellia sinensis, Populus trichocarpa, Populus alba, and Populus $x$ canadensis exhibited 84, 86, 54, 54, 54, 54, and 54\%, amino acid sequence identities, respectively (Fig. 1a). The multiple sequence alignment revealed the conservation of two metal ion-binding sites, an aspartate-rich DDXXD motif and an NDXXSXXXE (Fig. 1b), across all IspSs, including MpIspS. All known IspSs had an "isoprene score" as defined Sharkey et al. [24]. The devised score depends on how many of these four amino acids are the canonical F338, S445, F485, and N505. MpIspS had a score of 4 , as shown by the star in Fig. 1 b. In previous results, it has been suggested that these canonical residues are involved in substrate specificity $[24,25]$.

\section{Gene cloning, purification, and molecular mass determination}

The gene encoding the MpIspS (1683 bp) was codon-optimized, synthesized, subcloned, and expressed in E. coli (Additional file 1: Figure S1 and Fig. 2a). The enzyme was purified as a soluble protein from the crude extract obtained from harvested cells by immobilized metal affinity chromatography (IMAC). The purified MpIspS enzyme exhibited a single band of approximately $65 \mathrm{kDa}$ when analyzed by sodium dodecyl sulfate-polyacrylamide electrophoresis (SDS-PAGE) (Fig. 2b). This is consistent with the calculated molecular mass of 64,950 Da based on the 561 amino acid residues and six histidine residues as determined with the Compute $\mathrm{pI} / \mathrm{Mw}$ tool [26]. The native molecular mass of the MpIspS determined using Superose 12 10/300 gel filtration chromatography was estimated to be $65 \mathrm{kDa}$ as a monomer, based on the masses of reference proteins (Fig. 2c). In previous reports, the native molecular mass of IspSs from $P$. tremuloides and $P$. alba was reported as $121 \mathrm{kDa}$ as a dimer [27] and $68 \mathrm{kDa}$ as a monomer [10], respectively.

\section{Effects of metals on the activity of MplspS}

Various IspSs have been reported to require a divalent metal cofactor, such as a $\mathrm{Mg}^{2+}$ or $\mathrm{Mn}^{2+}$, for their activity, like other terpenoid synthases [10, 12]. Thus, we examined the effects that various divalent metals on MpIspS activity. The purified MpIspS enzyme displayed no activity following the removal of metal ions by treatment with ethylenediaminetetraacetic acid. Among the metal ions tested, $\mathrm{Mn}^{2+}$ was the most effective for MpIspS activity, with an optimal concentration of $5 \mathrm{mM}$ (Fig. 3a and b). By considering the highest activity with $\mathrm{Mn}^{2+}$ to be $100 \%$, activities of $91,86,79,74,53,48$, and $2 \%$ were detected in the presence of $\mathrm{Zn}^{2+}, \mathrm{Cu}^{2+}, \mathrm{Ni}^{2+}, \mathrm{Co}^{2+}, \mathrm{Mg}^{2+}, \mathrm{Ca}^{2+}$, and $\mathrm{Fe}^{2+}$, respectively. The observation of maximal activity of MpIspS in the presence of $\mathrm{Mn}^{2+}$ was interesting, given that all IspSs that have been characterized prefer $\mathrm{Mg}^{2+}$ as a cofactor [10,12, 13, 28]. In some cases, $\mathrm{Mn}^{2+}$ can partially substitute for $\mathrm{Mg}^{2+}[5,12,13]$. The IspS from Casuarina equisetifolia [29], Campylopus introflexus [30], and MpIspS (this study) displayed the highest activities in the presence of $\mathrm{Mn}^{2+}$, with the activities being less in the presence of $\mathrm{Mg}^{2+}$.

\section{Effects of $\mathrm{pH}$ and temperature on the activity of MplspS}

The MpIspS activity was examined over a $\mathrm{pH}$ range of 4.5-7.5 containing $5 \mathrm{mM} \mathrm{Mn}^{2+}$ or $1 \mathrm{mM} \mathrm{Mg}^{2+}$. The maximal enzyme activity was observed at $\mathrm{pH} 6.0$ and 


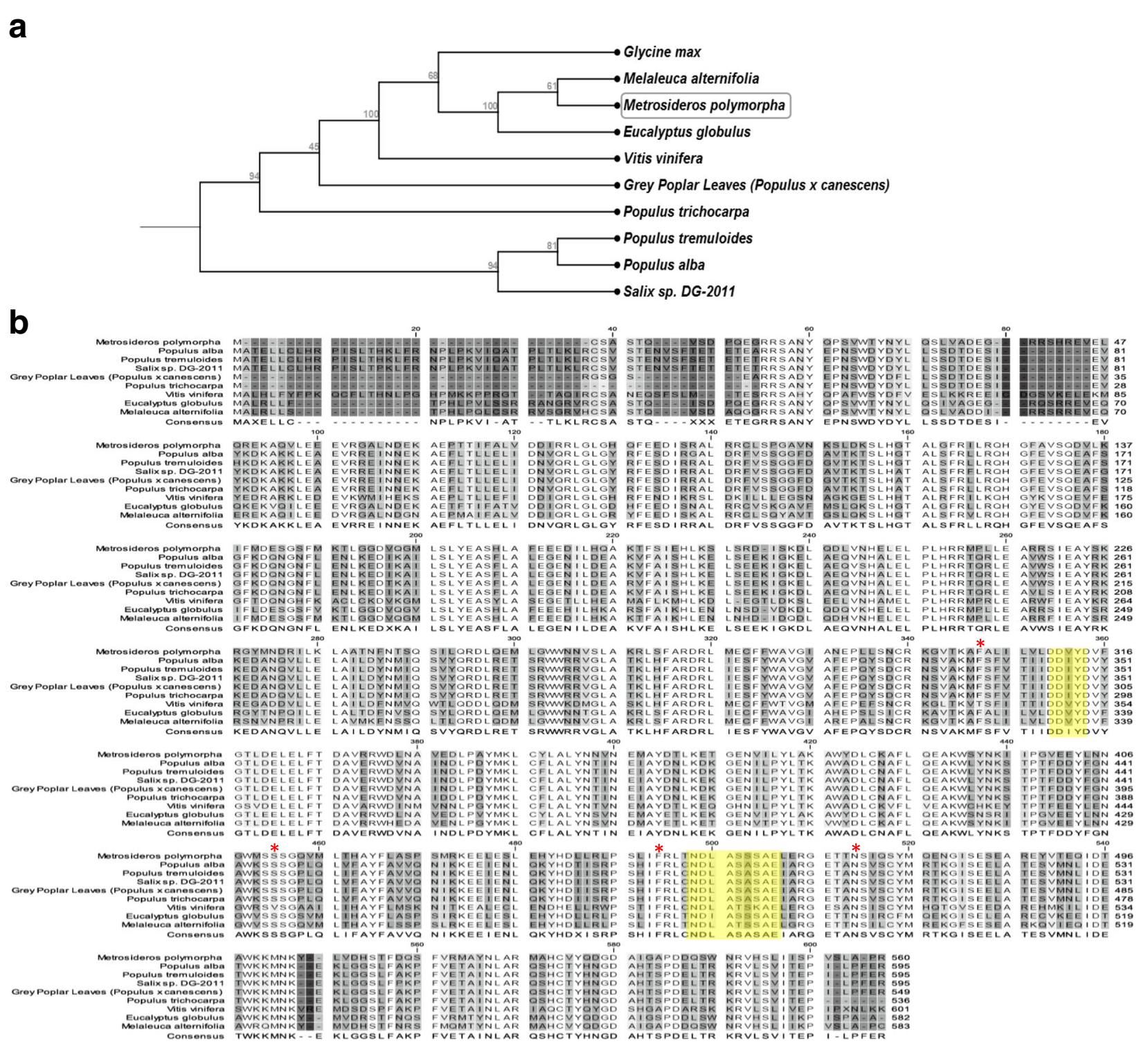

Fig. 1 Phylogenetic tree and sequence alignment of the MplspS with some known IspSs. a Phylogenetic tree of the retrieved MplspS and known IspS sequences. The bars represent evolutionary distance. b Alignment of amino acid sequences of IspSs. The GenBank accession numbers are: Populous alba, ADG96473.1; Populus tremuloides, Q7XAS7.1; Salix sp., AEK70967.1; Populus trichocarpa, ACD70404.1; Vitis vinifera, CAN65805.1; Eucalyptus globulus, BAF02831.1; Melaleuca alternifolia, AAP40638.1. Shaded sequences are the metal ions binding motif, DDXXD, and NDXXTXXXE. The canonical amino acid residues for isoprene synthases are boxed

$5 \mathrm{mM} \mathrm{Mn}^{2+}$ (Fig. 4a). At pH 5.5 and 7.0, the activity was approximately $40 \%$ of the maximum. Additionally, we tested the $\mathrm{pH}$ dependency in the presence of $\mathrm{Mg}^{2+}$ favorable for IspS activity. Maximal enzyme activity was observed at $\mathrm{pH}$ 6.0-6.5 and $1 \mathrm{mM} \mathrm{Mg}^{2+}$ (Additional file 2: Figure S2). The effect of temperature on enzyme activity was investigated. Maximum activity was recorded at $50{ }^{\circ} \mathrm{C}$ (Fig. 4b). At temperatures of 30 and $45{ }^{\circ} \mathrm{C}$, the activity was approximately $80 \%$ of the maximum. The maximum activity of various IspSs from Populus alba at $\mathrm{pH} 8$ and $40{ }^{\circ} \mathrm{C}$ [10], P. tremuloides at pH 8 and $32{ }^{\circ} \mathrm{C}$
[11, 12], Salix discolor at $\mathrm{pH} 8$ and $35^{\circ} \mathrm{C}$ [31], Campylopus introflexus at $\mathrm{pH} 8.6$ and $40{ }^{\circ} \mathrm{C}$ [30], Casuarina equisetifolia at pH 8 and $40{ }^{\circ} \mathrm{C}$ [29], Ficus septica at pH 9.5 and $40{ }^{\circ} \mathrm{C}$ [29], and $F$. virgate at $\mathrm{pH} 10$ and $40{ }^{\circ} \mathrm{C}$ [29] have been reported. Interestingly, previously characterized IspSs have been demonstrated to be active at a broad range of $\mathrm{pH}$ values with $\mathrm{pH}$ optima between 7 and 10. In addition, IspSs appear to have temperature optimum in the $35-40{ }^{\circ} \mathrm{C}$ range. Monoterpene synthases display $\mathrm{pH}$ optima ranging from 6 to 7 [32-34], because monoterpene synthases activity was related to 


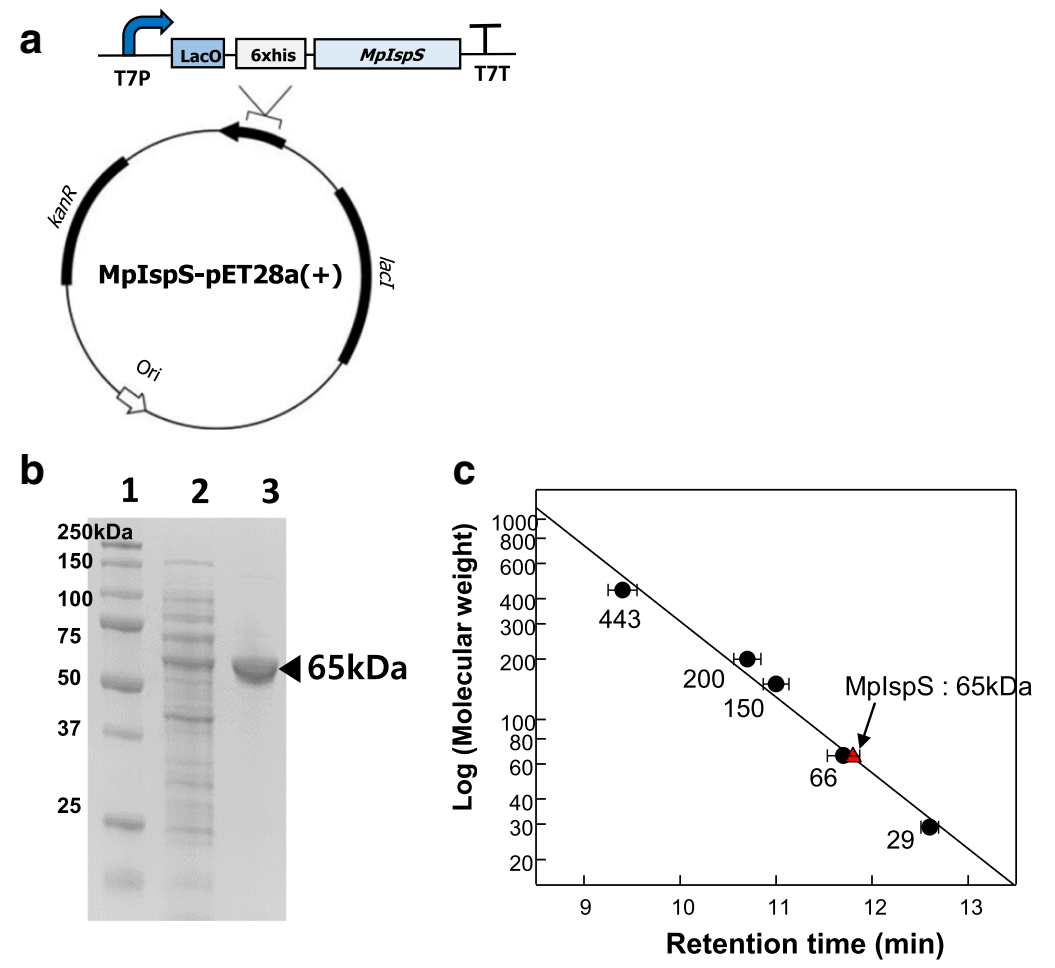

Fig. 2 SDS-PAGE analysis and determination of the molecular mass of MplspS. a Map of MplspS. Essential components of the vector are indicated. The MplspS coding region was cloned between the T7 promoter and terminator in vector pET-28a(+) containing the $\mathrm{N}$-terminal His 6 tag. b SDS-PAGE of MplspS. Lanes: 1, pre-stained marker protein (250, 150, 100, 75, 50, 37, and $25 \mathrm{kDa}$ ); 2, crude extract; 3, purified enzyme. c. Determination of the molecular mass of MplspS by gel-filtration chromatography. Reference proteins as closed circle were apoferritin (443 kDa), $\beta$-amylase $(200 \mathrm{kDa})$, alcohol dehydrogenase $(150 \mathrm{kDa})$, albumin $(13.7 \mathrm{kDa})$, and carbonic anhydrase $(29 \mathrm{kDa})$. MplspS is represented by the red triangle

chloroplast $\mathrm{pH}$ in plants. An acidic chloroplast $\mathrm{pH}$ and temperature above $40{ }^{\circ} \mathrm{C}$ favors the emission of monoterpenes [35]. M. polymorpha generally grows in acidic, weathered soils where the $\mathrm{pH}$ may be as low as 3.6 [36] and in the presence of terpene emission [23]. These ecological may be related with the $\mathrm{pH}$ optimum of MpIspS for isoprene conversion.

\section{Kinetic parameters of MplspS}

The kinetic parameters of purified recombinant MpIspS protein for DMAPP were determined. The curves of the Michaelis-Menten equation with the experimental data for DMAPP are shown in Fig. 5. MpIspS activity increased with increasing DMAPP concentration up to $15 \mathrm{mM}$, and higher concentrations inhibited the activity
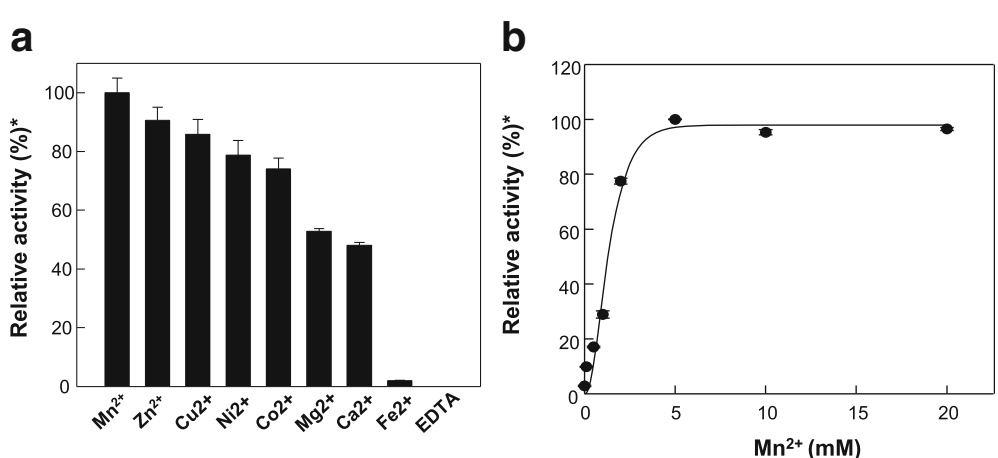

Fig. 3 Effect of metal ions on the activity of MplspS. a Effect of different metal ions on the activity of MplspS. The reactions were performed in $50 \mathrm{mM}$ MOPS buffer ( $\mathrm{pH}$ 6.0) containing $50 \mu \mathrm{M}$ DMAPP and $1 \mathrm{mM}$ of each metal ion, at $50{ }^{\circ} \mathrm{C}$ for $10 \mathrm{~min}$. $\mathbf{b}$ Effect of the concentration of Mn ${ }^{2+}$ on the activity of MplspS. * Relative activity of $100 \%$ was $17.5271 \mathrm{U} / \mathrm{mg}$ 
a

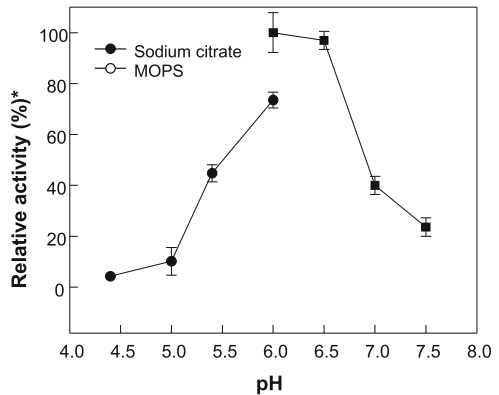

b

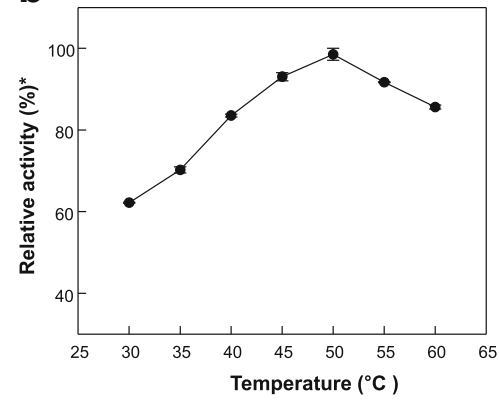

Fig. 4 Effects of $\mathrm{pH}$ and temperature on the activity of MplspS. a pH: The reactions were performed in $50 \mathrm{mM}$ sodium citrate (closed circle) or $50 \mathrm{mM}$ MOPS buffer (opened circle) containing $50 \mu \mathrm{M}$ DMAPP and $5 \mathrm{mM} \mathrm{Mn}^{2+}$ at $55^{\circ} \mathrm{C}$ for $10 \mathrm{~min}$. b Temperature: Reactions were performed in $50 \mathrm{mM}$ MOPS buffer ( $\mathrm{pH}$ 6.0) containing $50 \mu \mathrm{M}$ DMAPP and $5 \mathrm{mM} \mathrm{Mn}^{2+}$ of the enzyme for $10 \mathrm{~min}$. *Relative activity of $100 \%$ was $17.5271 \mathrm{U} / \mathrm{mg}$

under our assay conditions. Therefore, the $K_{\mathrm{m}}$ value was estimated by non-linear curve fitting of Michaelis-Menten formula at concentrations below $15 \mathrm{mM}$. Consequently, the $K_{\mathrm{m}}, k_{\mathrm{cat}}$, and $k_{\mathrm{cat}} / K_{\mathrm{m}}$ of MpIspS for DMAPP as substrate were $8.11 \mathrm{mM}, 21 \mathrm{~min}^{-1}$, and $2.59 \mathrm{mM}^{-}$ ${ }^{1} \min ^{-1}$, respectively. Turnover rates $\left(k_{\text {cat }}\right)$ for other IspSs are $1.7 \mathrm{~s}^{-1}$ for $P$. tremuloides [12], $1.8 \mathrm{~min}^{-1}$ for $P$. alba [10], $5.28 \mathrm{~min}^{-1}$ for P. montana [24], $0.66 \mathrm{~min}^{-1}$ for F. septica [29], and $0.9 \mathrm{~min}^{-1}$ for C. equisetifolia [29]. The $K_{m}$ values of IspSs from P. alba [29], F. septica [29], P. tremuloides [12], Salix discolor [5], and Quercus robur [14] are 15.9, 3.4, 8, 8, and $0.53 \mathrm{mM}$ respectively. Michaelis constants $\left(K_{m}\right)$ for IspS are usually very large compared to monoterpene or sesquiterpene synthases, which have apparent $K_{m}$ values in the $\mu \mathrm{M}$ range [7]. The large $K_{m}$ of isoprene synthases is evolutionarily

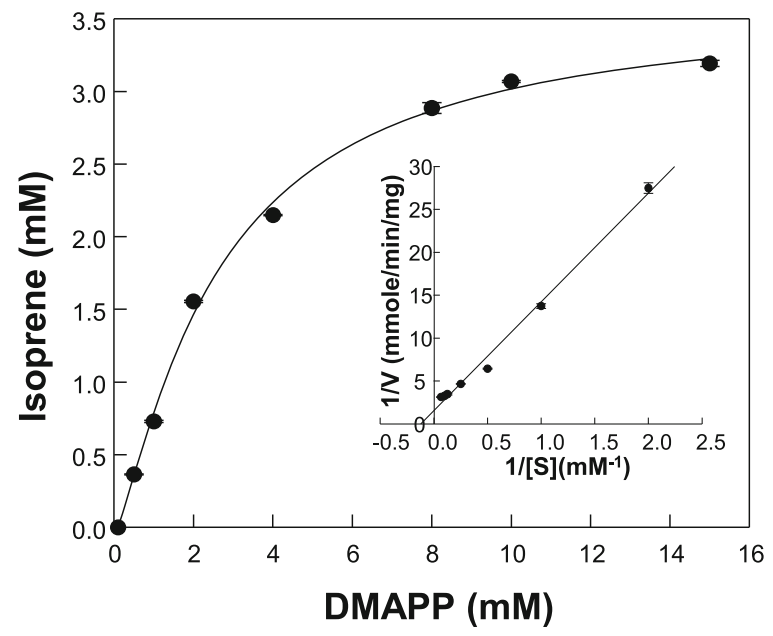

Fig. 5 Michaelis-Menten kinetics Michaelis-Menten plot of MplspS initial velocity versus substrate (DMAPP) concentration, monitoring production of isoprene. Reaction was in $50 \mathrm{mM}$ MOPS buffer ( $\mathrm{pH}$ 6.0) containing $5 \mathrm{mM} \mathrm{Mn}^{2+}$ and indicated concentration of DMAPP at $50{ }^{\circ} \mathrm{C}$ for $10 \mathrm{~min}$ advantageous by ensuring that carbon is first directed to essential physiological functions of the plant and only secondarily to isoprene production, because the main role of isoprene could be to alleviate abiotic stresses [7, 24]. Additionally, Sharkey proposed that isoprene serves to protect plant membranes against heat stress [37]. Eventually, for the biotechnological production of isoprene, the high $K_{m}$ and low activity of IspSs should be engineered because the requirement of high substrate (DMAPP) concentrations could become an obstacle to achieving high rates of isoprene synthesis.

\section{Isoprene production by $E$. coli expressing MplspS}

Wild-type E. coli can produce isoprene by the introduction of plant-derived IspS because it possesses an endogenous methylerythritol phosphate (MEP) pathway that is capable of which producing DMAPP. However, the amount of isoprene that is produced is very low because of the limited availability of DMAPP. In other studies, the MVA pathway has been reconstructed with multiple genes derived from various bacteria and yeast, and co-expressed along with IspS to enhance isoprene production by supplying enough amount of DMAPP $[15,17,19]$ (Fig. 6a). To determine the in vivo isoprene production by MpIspS from glycerol, an MpIspS expressing plasmid, pTSN-MpIspS was introduced into $E$. coli DH5 $\alpha$ with the exogenous MVA pathway encoded by pSEVA231-MVA plasmid (Fig. 6a). The E. coli strain expressing MpIspS in the presence of IPTG (Isopropyl $\beta$ - D - 1-thiogalactopyranoside) produced $23.3 \mathrm{mg} / \mathrm{L}$ at OD $4.6 \pm 0.4$ isoprene after 72 -h cultivation whereas the strain expressing MpIspS without IPTG as a control produced $0.43 \mathrm{mg} / \mathrm{mL}$ at OD $6.1 \pm 0.6$ (Fig. 6b), which resulted from leaky expression of MpIspS under the control of trc promoter. As expected, isoprene was not produced in cells harboring the pTSN plasmid (no IspS) and the pSEVA231-MVA plasmid (MVA pathway) 
Yeom et al. BMC Plant Biology (2018) 18:118

Page 6 of 10

a

Glycerol
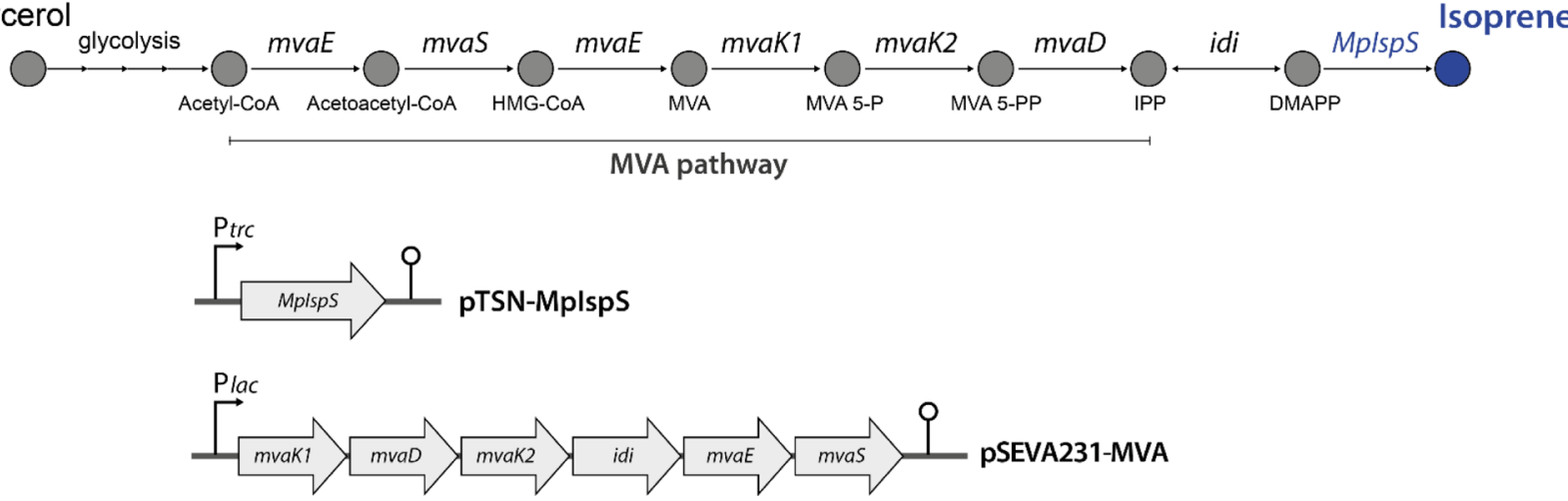

b

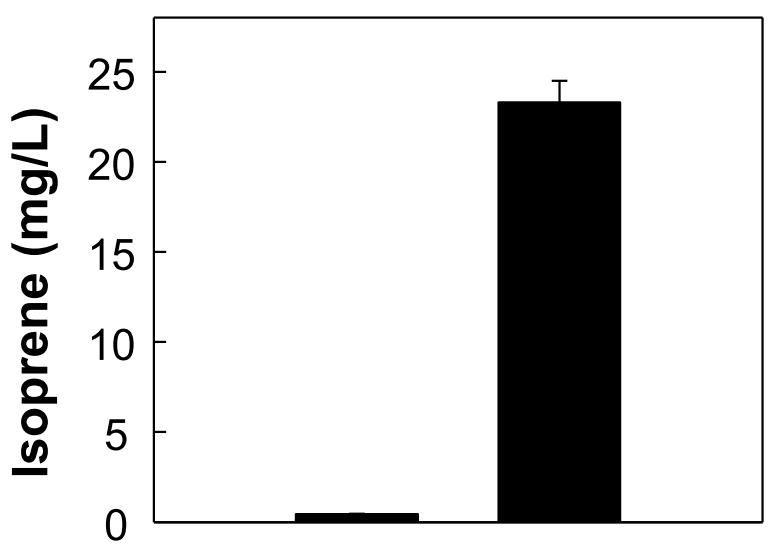

(-) IPTG (+) IPTG

Fig. 6 Isoprene production in E. coli. a Schematic representation of isoprene production pathway in an engineered E. coli harboring mevalonate (MVA) pathway genes. The isoprene production pathway from acetyl-CoA consists of seven enzymes: MvaE, Acetyl-CoA acetyltransferase/HMG-CoA reductase; MvaS, 3-hydroxy-3-methylglutaryl-CoA synthase; MvaK1, mevalonate kinase; MvaK2,

phosphomevalonate kinase; MvaD, mevalonate 5-diphosphate decarboxylase; Id, isopentenyl diphosphate isomerase; and MplspS, isoprene synthase. All enzymes were expressed from IPTG-inducible promoters (PArc promoter for isoprene synthase, Plac promoter for mevalonate pathway). $\mathbf{b}$ Isoprene production at $30{ }^{\circ} \mathrm{C}$ by E. coli expressing MplspS and MVA pathway genes with or without IPTG. Isoprene in the headspace was measured after $72 \mathrm{~h}$ incubation at $30^{\circ} \mathrm{C}$

(Additional file 2: Figure S2). The optimal culture conditons for maximal isoprene production by MpIspS along with the MVA pathway should be further studied. Although Isp from $P$. trichocarpa has the highest isoprene productivity among the reported IspSs [19], MpIspS could potentially be an enzyme for isoprene synthesis in various microorganisms.

Conclusions

In this work, we discovered a new Isp by sequence howology searches and identified the gene potentially encoding Isp M. polymorpha. The gene encoding the putative Isp from M. polymorpha was cloned, expressed in E. coli, purifled, and characterized. Recombinant MpIspS demonstrated Isp activity with a preference for $\mathrm{Mn}^{2+}$ as a cofactor, and its optimum $\mathrm{pH}$ and temperature were 6.0 and $50{ }^{\circ} \mathrm{C}$, respectively. The MpIspS was successfully used to produce isoprene from glycerol in E. coli expressing the heterologous MVA pathway genes. The MpIspS enzyme could be expressed in large amounts in E. coli, which led to increased enzymatic activity and resulted in high isoprene production in the E. coli. Based on our results, further protein engincering of MpIspS toward improved enzyme activity will pave the way for the high-level production of isoprene. Furthermore, engineered MpIspS in combination with the exogenous MVA pathway will be a platform for the enhanced production of isoprene in microorganisms. Overall, this study will provide a new Isp enzyme that is a useful key biocatalyst for isoprene production in engineered microbes.

Methods

Chemicals and materials

All chemical reagents used in this study were purchased from Sigma-Aldrich (St. Louis, MO, USA). 
Oligonucleotides and gene synthesis were provided by Macrogen (Seoul, Korea). Restriction endonucleases, polymerases, and DNA cloning kits were purchased from New England Biolabs (Ipswich, MA, USA). DNA preparation and manipulation techniques were carried out according to standard protocols for molecular biology. The kits of PCR product purification, gel extraction, and plasmid preparation were purchased from Promega (Madison, WI, USA). Profinia $^{\mathrm{m}}$ purification kits and all materials for SDS-PAGE were purchased from Bio-Rad (Hercules, CA, USA).

\section{Gene-mining of novel IspS}

To mine the novel IspS from the transcriptome datasets of plants belonging the family Fabaceae, Salicaceae, and Myrtaceae, approximately 113 GB of unassembled reads from the transcriptome projects (PRJDB3212, PRJNA275266, PRJNA296824, PRJNA232948, PRJEB10287, PRJNA203514, and PRJEB11301) were downloaded from the Sequence Read Archive website of GenBank. BLASTX searches of individual reads (E-value $\leq 1 \mathrm{e}^{-10}$ ) were performed against an in-house database consisting of IspSs and other terpene synthases retrieved from the GenBank database [38]. Reads assigned to IspS and other terpene synthases were extracted and sorted into sub-datasets of IspS and the other group. Reads in the IspS sub-datasets from each organism were assembled into six contigs using a sequence assembler. Open reading frames from each scaffold were identified using Prodigal v2.6.1 [39]. The predicted open reading frames were BLAST-searched against the UniProt databases [40]. Candidate isoprene synthase sequences were aligned using MUSCLE algorithm in the MEGA6 package program v.6.06 [41].

\section{Gene synthesis and cloning of MplspS}

The MpIspS (IspS from Metrosideros polymorpha) gene identified from gene mining was codon-optimized for $E$. coli using the by IDT Codon Optimization Tool (Integrated DNA Technologies Inc., Coralville, IA, USA; http://sg.idtdna.com/CodonOpt) and synthesized by Macrogen co. (Seoul, South Korea) (Additional file 3: Table S1). E. coli C2566 (New England Biolabs) and the pET-28a(+) plasmid (Novagen, Merck KGaA, Darmstadt, Germany) were used as host cells and expression vectors, respectively. The gene encoding MpIspS was amplified by PCR using the synthetic DNA as the template. The MpIspS coding region was cloned between the T7 promoter and terminator in the $\mathrm{pET}-28 \mathrm{a}(+)$ plasmid containing an N-terminal $\mathrm{His}_{6}$ tag. Forward $\left(5^{\prime}-\mathrm{CGGC}\right.$ AGCCATATGTGTAGTG-3') and reverse (5'-GGTG GTGCTCGAGTTAACGCGG-3') primers were designed for the introduction of the NdeI and XhoI restriction sites (underlined), respectively. The PCR product was subcloned into the pET-28a(+) plasmid digested with the same restriction enzymes and then transformed into $E$. coli $\mathrm{C} 2566$. For isoprene production in $E$. coli, we constructed an MpIspS-expressing plasmid (pTSN-MpIspS). Forward (5'-ACACAGGAGGTTAA ACCATGTGTAGTGCTTCCACACAAGT-3') and reverse (5'-CATGCCTGCAGGTCGACTCTAGAT TAACGC-3') primers were designed and the MpIspS coding region was amplified by PCR using the synthetic DNA as the template. Vector backbone was prepared after digestion of the pTSN plasmid [42] with NcoI and $X b a \mathrm{I}$, and then the PCR product was ligated into the digested pTSN plasmid using the Gibson Assembly Master Mix (New England Biolabs). For MVA pathway expression, we constructed the pSEVA231-MVA plasmid. The first fragment containing the lacI gene was amplified using forward (5'-TCACACAGGACGAAGCGGC ATGCATTTACG-3') and reverse (5'-GCGTTCGAA CGGCAGAATTGCAGCTCATTTCAGAATATTT-3')

primers from the pSNA-MrBBS plasmid containing MVA pathway genes [42], the second fragment containing MVA pathway genes was amplified using forward (5' -CAATTCTGCCGTTCGAACGCTAATCTAGA GCGCAACGCAA-3') and reverse (5'-CAGTCACGA CAAGAGTTTGTAGAAACGCAA-3') primers from the pSNA-MrBBS plasmid as template, and the third fragment as vector backbone was amplified using forward (5' - ACAAACTCTTGTCGTGACTGGGAAAACCC

T-3') and reverse (5' - TGCCGCTTCGTCCTGTGTG AAATTGTTATC-3') primers from the pSEVA231 plasmid [43]. The three fragments were assembled using the Gibson Assembly Master Mix (New England Biolabs). The correctness of the constructed plasmid was confirmed by Sanger sequencing (Macrogen).

\section{MplspS purification}

The MpIspS expressing cells were harvested from culture broth and disrupted on ice using ultrasonication (Thermo Fisher Scientific, Waltham, MA, USA) in buffer A $(50 \mathrm{mM}$ sodium monophosphate, $300 \mathrm{mM} \mathrm{NaCl}$, $10 \mathrm{mM}$ imidazole, and $0.1 \mathrm{mM}$ phenylmethylsulfonyl fluoride as a protease inhibitor). Unbroken cells and cell debris were removed by centrifugation at $14,000 \mathrm{rpm}$ for $10 \mathrm{~min}$ at $4{ }^{\circ} \mathrm{C}$, and the supernatants were filtered through a $0.45 \mu \mathrm{m}$ filter and applied to an IMAC column (Bio-Rad) equilibrated with buffer A. Supernatants collected from lysates were loaded into the Profinia ${ }^{\text {тм }}$ Purification System (Bio-Rad). Supernatants were loaded onto a 1-mL IMAC cartridge and washed twice with 5 and $10 \mathrm{mM}$ imidazole buffer A. Proteins were eluted with $250 \mathrm{mM}$ imidazole in buffer A. Imidazole and other salts were removed and changed with $50 \mathrm{mM}$ MOPS buffer ( $\mathrm{pH}$ 6.0) using a desalting cartridge. The resulting solution was used as the purified MpIspS enzyme. The protein concentration was quantified by the standard 
Bradford method [44]. The purified proteins were confirmed by SDS-PAGE.

\section{Molecular mass determination of MplspS}

The subunit molecular mass of MpIspS was examined by SDS-PAGE under denaturing conditions, using the proteins of a pre-stained ladder (Bio-Rad) as reference proteins. All protein bands were stained with Coomassie Blue for visualization. The native molecular mass of the enzyme was determined by gel-filtration chromatography on a Superose 12 10/300 GL column (GE Healthcare, Buckinghamshire, UK). The purified enzyme was applied to the column and eluted with $25 \mathrm{mM}$ Tris- $\mathrm{HCl}$ (pH 7.4) buffer containing $200 \mathrm{mM} \mathrm{NaCl}$ at a flow rate of $1 \mathrm{~mL} / \mathrm{min}$. The column was calibrated with apoferritin $(443 \mathrm{kDa}), \beta$-amylase $(200 \mathrm{kDa})$, alcohol dehydrogenase $(150 \mathrm{kDa})$, albumin $(13.7 \mathrm{kDa})$, and carbonic anhydrase $(29 \mathrm{kDa})$ as reference proteins (Sigma-Aldrich), and the native molecular mass of the enzyme was calculated by comparing with the migration length of reference proteins.

\section{Effects of metal ions, $\mathrm{pH}$, and temperature}

To evaluate the effect of metal ions on enzyme activity, an enzyme assay was conducted after the treatment with $1 \mathrm{mM}$ ethylenediaminetetraacetic acid at $4{ }^{\circ} \mathrm{C}$ for $1 \mathrm{~h}$ or after addition a $1 \mathrm{mM}$ concentration of each metal ion $\left(\mathrm{Mn}^{2+}, \mathrm{Zn}^{2+}, \mathrm{Cu}^{2+}, \mathrm{Ni}^{2+}, \mathrm{Co}^{2+}, \mathrm{Mg}^{2+}, \mathrm{Ca}^{2+}\right.$, or $\left.\mathrm{Fe}^{2+}\right)$. The reactions were performed in $50 \mathrm{mM}$ MOPS buffer (pH 6.0) containing each metal ion at $50{ }^{\circ} \mathrm{C}$. To examine the effect of $\mathrm{pH}$ on the activity of MpIspS, the $\mathrm{pH}$ was varied between 4.5 and 7.5 using $50 \mathrm{mM}$ sodium citrate (pH 4.5-6.0) and $50 \mathrm{mM}$ MOPS buffer (3-(N-morpholino)propanesulfonic acid; pH 6-7.5) containing $5 \mathrm{mM}$

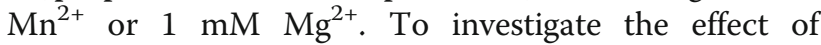
temperature on MpIspS enzyme activity, the temperature was varied from 30 to $60{ }^{\circ} \mathrm{C}$. One unit (U) of MpIspS activity was defined as the amount of enzyme required to produce $1 \mu \mathrm{M}$ of isoprene per min at $50{ }^{\circ} \mathrm{C}$ and $\mathrm{pH} 6.0$.

\section{Analytical method}

To measure isoprene concentration as described previously [30], $50 \mu \mathrm{L}$ headspace of the sealed serum bottle used for the enzyme reaction or the cultivation of the engineered $E$. coli was directly injected into the GC system equipped with a flame ionization detector (FID) and an HP-5 column $(30 \mathrm{~m} \times 0.320 \mathrm{~mm} \times 0.25 \mu \mathrm{m})$ at a flow rate of $1 \mathrm{~mL} / \mathrm{min}$. The starting temperature of the oven was maintained at $40{ }^{\circ} \mathrm{C}$ for $3 \mathrm{~min}$, then was increased by $10{ }^{\circ} \mathrm{C} / \mathrm{min}$ to $100{ }^{\circ} \mathrm{C}$, held at $100{ }^{\circ} \mathrm{C}$ for $3 \mathrm{~min}$, increased at the rate of $30{ }^{\circ} \mathrm{C} / \mathrm{min}$ to $200{ }^{\circ} \mathrm{C}$, and then again held at $200{ }^{\circ} \mathrm{C}$ for $1 \mathrm{~min}$. Commercial isoprene (Sigma-Aldrich) was used as an external standard for the quantification of isoprene. The retention time (R.T.) of the standard isoprene was $2.8 \mathrm{~min}$.

\section{Kinetic parameters}

Various concentrations of DMAPP $(0-10 \mathrm{mM})$ were used to determine the kinetic parameters of the MpIspS enzyme. The reaction was conducted in $50 \mathrm{mM}$ MOPS buffer (pH 6.0) containing $5 \mathrm{mM} \mathrm{Mn}^{2+}$ at $50{ }^{\circ} \mathrm{C}$ for $10 \mathrm{~min}$. The amounts of isoprene in the headspace were detected by GC-FID. The enzyme kinetic parameters, $K_{m}$ and $k_{\text {cat }}$ values for substrates, were determined by fitting the data to the Michaelis-Menten equation.

Bioisoprene production by $E$. coli expression with MplspS For isoprene production in E. coli, pTSN-MpIspS, and pSEVA231-MVA were co-transformed into $E$. coli DH5 $\alpha$. Transformants were selected on LB (10 g/L tryptone, $5 \mathrm{~g} / \mathrm{L}$ yeast extract, and $10 \mathrm{~g} / \mathrm{L} \mathrm{NaCl}$ ) agar plates containing $100 \mu \mathrm{g} / \mathrm{mL}$ ampicillin and $25 \mu \mathrm{g} / \mathrm{mL}$ kanamycin and incubated at $30{ }^{\circ} \mathrm{C}$ for $16 \mathrm{~h}$. To prepare the seed culture, a single colony was cultivated in LB media containing $100 \mu \mathrm{g} / \mathrm{mL}$ ampicillin and $25 \mu \mathrm{g} / \mathrm{mL}$ kanamycin at $30{ }^{\circ} \mathrm{C}$ for $16 \mathrm{~h}$. Culture for isoprene production was conducted in a sealed bottle containing $500 \mu \mathrm{L}$ TB medium (24 g/L yeast extract, $12 \mathrm{~g} / \mathrm{L}$ tryptone, $9.2 \mathrm{~g} / \mathrm{L}$ $\mathrm{K}_{2} \mathrm{HPO}_{4}$, and $\left.2.2 \mathrm{~g} / \mathrm{L} \mathrm{KH}_{2} \mathrm{PO}_{4}\right)$ containing $0.025 \mathrm{mM}$ IPTG, $100 \mu \mathrm{g} / \mathrm{mL}$ ampicillin, $25 \mu \mathrm{g} / \mathrm{mL}$ kanamycin, and $3.5 \%(w / v)$ glycerol as the main carbon source at $30{ }^{\circ} \mathrm{C}$ for 3 days. After cultivation, isoprene in the headspace was analyzed by GC-FID.

\section{Additional files}

Additional file 1: Figure S1. Effects of $\mathrm{pH}$ and temperature on activity of MplspS. A. pH: The reactions were performed in $50 \mathrm{mM}$ sodium citrate (circle) or $50 \mathrm{mM}$ MOPS buffer (square) containing $50 \mu \mathrm{M}$ DMAPP and $5 \mathrm{mM} \mathrm{Mn}^{2+}$ (closed symbol) or $1 \mathrm{mM} \mathrm{Mg}^{2+}$ (open symbol) at $55^{\circ} \mathrm{C}$ for $10 \mathrm{~min}$. B. Temperature: Reactions were performed in $50 \mathrm{mM}$ MOPS buffer ( $\mathrm{pH}$ 6.0) containing $50 \mu \mathrm{M}$ DMAPP and $5 \mathrm{mM} \mathrm{Mn}^{2+}$ for $10 \mathrm{~min}$. *Relative activity of $100 \%$ was $17.5271 \mathrm{U} / \mathrm{mg}$. (PPT $141 \mathrm{~kb}$ )

Additional file 2: Figure S2. GC-MS analysis of isoprene from the head space in culture for MPIspS3 and MVA pathway harboring E. coli. Isoprene, MPIspS3 product, and empty vector represent commercial isoprene as standard, product from MPIspS3 and MVA pathway harboring E. coli, and product from $\mathrm{pET} 28 \mathrm{a}(+)$ and MVA pathway harboring $E$. coli, respectively. (PPT $186 \mathrm{~kb}$ )

Additional file 3: Table S1. Gene sequences of IspS from Metrosideros polymorpha. (PPT $140 \mathrm{~kb}$ )

\section{Abbreviations}

DMAPP: Dimethylallyl diphosphate; IPTG: Isopropyl $\beta-$ D - 1thiogalactopyranoside; IspS: Isoprene synthase; MEP: Methylerythritol phosphate; MplspS: Isoprene synthase from Metrosideros polymorpha; MVA: Mevalonate

\section{Acknowledgments}

We appreciate the assistance of Dr. Byung Kwon Kim (OmicsPia, Inc., Daejeon, Korea) for bioinformatics analyses. And also, the authors would like to thank Dr. Victor D. Lorenzo for the kind donation of the pSEVA plasmids. 


\section{Funding}

This research was supported by C1 Gas Refinery Program through the National Research Foundation of Korea (NRF) funded by the Ministry of Science and ICT (NRF-2018M3D3A1A01055732), the Intelligent Synthetic Biology Center of the Global Frontier Project (2011-0031944) and the KRIBB Research Initiative Program.

\section{Availability of data and materials}

The datasets supporting the conclusions of this article are included within the article and its Additional files.

\section{Authors' contributions}

SY and MK designed and performed experiments and wrote the manuscript. SKK, KKK, and HL performed experiments for isoprene production and revised the manuscript. DK, DL, HK, and SL revised the manuscript and prepared it for submission. All authors reviewed the results and approved the manuscript.

\section{Ethics approval and consent to participate}

Not applicable.

\section{Competing interests}

The authors declare that they have no competing interests.

\section{Publisher's Note}

Springer Nature remains neutral with regard to jurisdictional claims in published maps and institutional affiliations.

\section{Author details}

${ }^{1}$ Synthetic Biology and Bioengineering Research Center, KRIBB, Daejeon 34141, Republic of Korea. 'Department of Chemical Engineering and Applied Chemistry, Chungnam National University, Daejeon 34113, Republic of Korea. ${ }^{3}$ Department of Biosystems and Bioengineering, KRIBB School of Biotechnology, University of Science and Technology, Daejeon 34113 Republic of Korea.

\section{Received: 13 November 2017 Accepted: 21 May 2018} Published online: 15 June 2018

\section{References}

1. H Z, M S, SW H: Compositions and methods for the production of isoprene. In. Edited by patent U. USA; 2012

2. Ilmén M, Oja M, Huuskonen A, Lee S, Ruohonen L, Jung S. Identification of novel isoprene synthases through genome mining and expression in Escherichia coli. Metab Eng. 2015;31:153-62.

3. Stephanopoulos $\mathrm{G}$. Challenges in engineering microbes for biofuels production. Science. 2007:315(5813):801-4.

4. Clomburg JM, Gonzalez R. Biofuel production in Escherichia coli: the role of metabolic engineering and synthetic biology. Appl Microbiol Biotechnol. 2010;86(2):419-34

5. Mary C. Wildermuth, ray fall: biochemical characterization of stromal and thylakoid-bound isoforms of isoprene synthase in willow leaves. Plant Physiol. 1998;116:1111-23.

6. Weissermel K, Arpe H-J. Industrial Organic Chemistry: 3rd edn. New York: VCH Publishers; 1997.

7. Ye L, LV X, Yu H. Engineering microbes for isoprene production. Metab Eng. 2016;38:125-38.

8. Beck ZO Cervin MA, Nielsen AT, Peres CM: Compositions and methods of pgl for the increased production of isoprene. In., vol. US8455236 B2. USA; 2013.

9. Sharkey TD, Yeh S, Wiberley AE, Falbel TG, Gong D, Fernandez DE. Evolution of the isoprene biosynthetic pathway in kudzu. Plant Physiol. 2005;137(2): 700-12.

10. Sasaki K, Ohara K, Yazaki K. Gene expression and characterization of isoprene synthase from Populus alba. FEBS Lett. 2005:579(11):2514-8.

11. Silver GM, Fall R. Enzymatic synthesis of isoprene from dimethylallyl diphosphate in aspen leaf extracts. Plant Physio. 1991;97(4):1588-91.

12. Silver GM, Fall R. Characterization of apen isoprene synthase, an enzyme responsible for leaf isoprene emission to the atmosphere. J Biol Chem. 1995;270(22):13010-6.
13. Kuzma J, Fall R. Leaf isoprene emission rate is dependent on leaf development and the level of isoprene synthase. Plant physio. 1993;101(2): 435-40.

14. Lehning A, Zimmer I, Steinbrecher R, Brüggemann N, Schnitzler JP. Isoprene synthase activity and its relation to isoprene emission in Quercus robur $\mathrm{L}$. leaves. Plant. Cell Environ. 1999;22(5):495-804.

15. Yang J, Xian M, Su S, Zhao G, Nie Q, Jiang X, Zheng Y, Liu W. Enhancing production of bio-isoprene using hybrid MVA pathway and isoprene synthase in E. coli. PLoS One. 2012;7(4):e33509.

16. Zhao Y, Yang J, Qin B, Li Y, Sun Y, Su S, Xian M. Biosynthesis of isoprene in Escherichia coli via methylerythritol phosphate (MEP) pathway. Appl Microbiol Biotechnol. 2011;90(6):1915-22.

17. Yang J, Zhao G, Sun Y, Zheng Y, Jiang X, Liu W, Xian M. Bio-isoprene production using exogenous MVA pathway and isoprene synthase in Escherichia coli. Bioresour Technol. 2012:104:642-7.

18. Liu H, Sun Y, Ramos KRM, Nisola GM, Valdehuesa KNG, Lee WK, Park SJ, Chung W-J. Combination of entner-doudoroff pathway with MEP increases isoprene production in engineered Escherichia coli. PLoS One. 2013:8(12):e83290.

19. Kim JH, Wang C, Jang HJ, Cha MS, Park JE, Jo SY, Choi ES, Kim SW. Isoprene production by Escherichia coli through the exogenous mevalonate pathway with reduced formation of fermentation byproducts. Microb Cell Factories. 2016;15(1):214

20. Lv X, Wang F, Zhou P, Ye L, Xie W, Xu H, Yu H. Dual regulation of cytoplasmic and mitochondrial acetyl-CoA utilization for improved isoprene production in Saccharomyces cerevisiae. Nat Commun. 2016;7:12851.

21. Lindberg P, Park S, Melis A. Engineering a platform for photosynthetic isoprene production in cyanobacteria, using Synechocystis as the model organism. Metab Eng. 2010;12(1):70-9.

22. Xue J, Ahring BK. Enhancing isoprene production by genetic modification of the 1-deoxy-d-xylulose-5-phosphate pathway in Bacillus subtilis. Appl Environ Microbiol. 2011:77(7):2399-405.

23. Llusià J, Peñuelas J, Sardans J, Owen SM, Niinemets Ü. Measurement of volatile terpene emissions in 70 dominant vascular plant species in Hawaii: aliens emit more than natives. Glob Ecol Biogeogr. 2010;19: 863-74.

24. Sharkey TD, Gray DW, Pell HK, Breneman SR, Topper L. Isoprene synthase genes form a monophyletic clade of acyclic terpene synthases in the TPS-B terpene synthase family. Evol Int J Org Evol. 2013;67(4):1026-40.

25. Li M, Xu J, Algarra Alarcon A, Carlin S, Barbaro E, Cappellin L, Velikova V, Vrhovsek U, Loreto F, Varotto C. In planta recapitulation of isoprene synthase evolution from Ocimene synthases. Mol Biol Evol. 2017;34(10): 2583-99.

26. Wilkins MR, Gasteiger E, Bairoch A, Sanchez JC, Williams KL, Appel RD, Hochstrasser DF. Protein identification and analysis tools in the ExPASy server. Methods Mol Biol. 1999;112:531-52.

27. Silver GM, Fall R. Characterization of aspen isoprene synthase, an enzyme responsible for leaf isoprene emission to the atmosphere. J Biol Chem. 1995:270(22):13010-6.

28. Schnitzler J-P, Arenz R, Steinbrecher R, Lehning A. Characterization of an isoprene synthase from leaves of Quercus petraea (Mattuschka) Liebl. Botanica Acta. 1996;109:216-21.

29. Oku $H$, Inafuku $M$, Ishikawa $T$, Takamine $T$, Ishmael $M$, Fukuta $M$. Molecular cloning and biochemical characterization of isoprene synthases from the tropical trees Ficus virgata, Ficus septica, and Casuarina equisetifolia. J Plant Res. 2015;128(5):849-61.

30. Lantz AT, Cardiello JF, Gee TA, Richards MG, Rosenstiel TN, Fisher AJ. Biochemical characterization of an isoprene synthase from Campylopus introflexus (heath star moss). Plant Physiol Biochem. 2015;94:209-15.

31. Wildermuth MC, Fall R. Light-dependent isoprene emission (characterization of a thylakoid-bound isoprene synthase in Salix discolor chloroplasts). Plant Physiol. 1996;112(1):171-82.

32. Bohlmann J, Meyer-Gauen G, Croteau R. Plant terpenoid synthases: molecular biology and phylogenetic analysis. Proc Natl Acad Sci U S A. 1998;95(8):4126-33

33. Fischbach RJ, Zimmer I, Steinbrecher R, Pfichner A, Schnitzler JP. Monoterpene synthase activities in leaves of Picea abies (L.) karst. And Quercus ilex L. Phytochemistry. 2000:54(3):257-65.

34. Niinemets U, Seufert G, Steinbrecher R, Tenhunen JD. A model coupling foliar monoterpene emissions to leaf photosynthetic characteristics in Mediterranean evergreen Quercus species. New Phytol. 2002;153:257-75. 
35. Dindorf T, Kuhn U, Ganzeveld L, Schebeske G, Ciccioli P, Holzke C, Köble R Seufert G, Kesselmeier J. Significant light and temperature dependent monoterpene emissionsfrom European beech (Fagus sylvatica L.) and their potential impacton the European volatile organic compound budget. J Geophys Res. 2006;111:D16305.

36. Friday JB, Herbert DA. Metrosideros polymorpha ('öhi'a lehua). Spec Prof Pac Is| Agroforest. 2006;3:2.

37. Sharkey TD. Is it useful to ask why plants emit isoprene? Plant Cell Environ. 2013;36(3):517-20

38. Altschul SF, Madden TL, Schaffer AA, Zhang J, Zhang Z, Miller W, Lipman DJ. Gapped BLAST and PSI-BLAST: a new generation of protein database search programs. Nucleic Acids Res. 1997;25(17):3389-402

39. Hyatt D, Chen GL, Locascio PF, Land ML, Larimer FW, Hauser L. Prodigal: prokaryotic gene recognition and translation initiation site identification. BMC Bioinformatics. 2010;11:119.

40. Wu CH, Apweiler R, Bairoch A, Natale DA, Barker WC, Boeckmann B, Ferro S, Gasteiger E, Huang H, Lopez R, et al. The universal protein resource (UniProt): an expanding universe of protein information. Nucleic Acids Res. 2006;34(Database issue):187-91.

41. Tamura K, Stecher G, Peterson D, Filipski A, Kumar S. MEGA6: molecular evolutionary genetics analysis version 6.0. Mol Biol Evol. 2013;30(12):2725-9.

42. Han GH, Kim SK, Yoon PK, Kang Y, Kim BS, Fu Y, Sung BH, Jung HC, Lee DH, Kim SW, et al. Fermentative production and direct extraction of (-)-abisabolol in metabolically engineered Escherichia coli. Microb Cell Factories. 2016;15(1):185

43. Silva-Rocha R, Martinez-Garcia E, Calles B, Chavarria M, Arce-Rodriguez A, de Las Heras A, Paez-Espino AD, Durante-Rodriguez G, Kim J, Nikel PI, et al. The standard European vector architecture (SEVA): a coherent platform for the analysis and deployment of complex prokaryotic phenotypes. Nucleic Acids Res. 2013;41(Database issue):D666-75.

44. MM B. A rapid and sensitive method for the quantification of microgram quantities of protein utilizing the principle of protein-dye binding. Anal Biochem. 1976:72:248-54.

\section{Ready to submit your research? Choose BMC and benefit from}

- fast, convenient online submission

- thorough peer review by experienced researchers in your field

- rapid publication on acceptance

- support for research data, including large and complex data types

- gold Open Access which fosters wider collaboration and increased citations - maximum visibility for your research: over $100 \mathrm{M}$ website views per year 